\title{
BRASIL IN TEIAS CULTURAIS: MAPA DE QUESTÕES E PARCERIAS EPISTEMOLÓGICAS TRANSNACIONAIS POSSÍVEIS, FORA DE EIXOS HEGEMÔNICOS
}

\author{
Osmar Moreira dos Santos
}

\begin{abstract}
Aranha - É o espírito da vingança o de ressentimento. O seu poder de contágio é o veneno. A sua vontade é uma vontade de punir e de julgar. A sua arma é o fio, o fio da moral. A sua pregação é a igualdade (que toda a gente se torne semelhante a si mesmo!) - Dicionário dos principais personagens de Nietzsche, p. 40, in: Deleuze. Nietzsche. "Parabéns, por esse evento lindo: espalhado pelo mundo". Marinela Freitas, Porto - Portugal, mesa 19: Diálogos para além do Atlântico: Crítica Cultural e intersexualidades.

“Fora do eixo Rio-São Paulo, evento dessa magnitude organizado por uma universidade pública brasileira, e nesses tempos difíceis, nos enche de esperança; por isso estou divulgando-o pelo Brasil e pelo mundo" - Lídia Santos, escritora brasileira radicada nos EUA, mesa 2: Literatura Brasileira nos Estados Unidos e a Literatura Brasileiro-Americana: o olhar dos autores;

"Gostava de propor feiras internacionais de teatro, onde grupo e parceiros trocam ideias sobre a encenação cultural através das plataformas digitais tendo em conta a pandemia. Através de manifestação de cada cultura perceber o nível que cada povo foi afetado pela covid - 19 . Ex: em Moçambique temos várias etnias e eu faço parte dos Tsongas, e poderia desenvolver uma peça teatral a falar do sofrimento que os Tsongas estão a passar nesse período e assim, cada povo traria uma peça desenvolvendo [formas de representar] o sofrimento do mesmo". Nechen Isabel Dique (um dos 1.265 inscritos no evento).
\end{abstract}

Resumo: Trata-se de um balanço teoricamente referenciado sobre o I Congresso Brasil in Teias Culturais avaliando seus resultados a partir de uma imagen do Brasil deslocada dos clichês interpretativos de sua cultura intelectual dominante e comprometida com o stablishment. Ao empreeendermos um olhar sobre o Brasil a partir do pensamento africano e asiático e suspendendo por um tempo preciso o imperativo ocidental, seja por força de seus próprios críticos, seja pelo pensamento combativo contra- 
ocidental, tornamos visíveis novas paisagens, novos horizontes para se construimos, com certa urgencia, um outro mundo possível.

Palavras-chave: Brasil libertário; conexões afro-asiáticas; profanações; socialismo ou barbarie.

\title{
BRAZIL IN CULTURAL WEBS: MAP OF POSSIBLE TRANSNATIONAL EPISTEMOLOGICAL ISSUES AND PARTNERSHIPS, OUTSIDE HEGEMONIC AXES
}

\begin{abstract}
It is a theoretically referenced balance about the I Congress Brasil in cultural webs evaluating its results from an image of Brazil displaced from the inter-pretentious clichés of its dominant intellectual culture and committed to the establishment. By taking a look at Brazil from african and asian thinking and suspending the western imperative for a precise time, either by virtue of its own critics or by combative counter-western thinking, we make new landscapes, new horizons to build, with some urgency, another possible world.
\end{abstract}

Keywords: libertarian Brazil; afro-asian connections; desecrations; socialism or barbarism.

\section{Introdução}

Os objetivos desse I Congresso Internacional Brasil in Teias Culturais: relações internacionais sob o crivo da crítica cultural foram: selecionar imagens culturais brasileiras libertárias e em condições de empreender diálogos transculturais emancipatórios; construir redes de cooperação científicas on-line, alternativas, sem o peso reativo das institucionalidades burocráticas; propor e estimular formas de pensamento não subjugadas a sistemas intelectuais etnocidas ou aprisionadas ao imaginário medieval e colonial, que não cessam de retornar. E com esses objetivos, envolvendo escritores, artistas, professores(as) e pesquisadores (as) de todos os continentes, problematizar a imagem do Brasil em outras teias culturais, tecidas a ferro e fogo por mais de cinco séculos, e, sob o crivo da crítica cultural, redimensionar essas linhas da teia, fazendo emergir novos pontos-acontecimentos: urdidos, agora, sem o peso do ressentimento e da má consciência, que sempre atravessou o espírito das três personagens da paixão 
triste, a saber: os exploradores, os explorados e aqueles que se entristecem com esse enredamento.

Esses objetivos mencionados acima pressupõem também, e de modo duplo, indireto e dialeticamente concebidos, um outro Brasil aprisionado em outras teias culturais, as da cultura do dinheiro, desde que foi ocupado, há mais de 500 anos, pela empresa colonial e mercantilista europeia e, nos últimos dois séculos, pelo capitalismo e seu imperialismo abutre.

Assim, esse Brasil ocupado, se insere em outro tipo de teias, a saber, é o paraíso e a salvação do imaginário medieval decadente e genocida; o lugar de vastas dimensões territoriais a serem ocupadas por agentes e/ou famílias próximas aos reis e aos empresários de todos os setores; o lugar, onde desde sempre, têm ocorrido sistematicamente as ordens de despejo linguístico, cultural, territorial e ontológico dos povos originários ou de povos traficados da África, aqui tratados como coisas; e como se não bastasse, temos ainda o lugar onde as instituições de estado pouquíssimas vezes realizarem a mediação entre o capital e o trabalho com a função de reduzir as desigualdades sociais mais alarmantes do mundo, mas, ao contrário, o estado, aqui, além de ser o gerente do capital, aprisiona o sistema intelectual, de ponta a ponta, a ponto de se criminalizar qualquer programa educativo que vise alfabetizar seus jovens e adultos para uma cultura política emancipatória e/ou uma política cultural, que problematize a cultura como um "bom negócio" ou "macumba pra turistas", e conceba a cultura como um bem simbólico, um direito de todos ao acesso a bens universais, a equipamentos de produção, circulação, consumo e geração de rendas.

O principal dispositivo, então, de divulgação desse Brasil aprisionado em teias da cultura do dinheiro, é a Rede Globo de televisão que, espalhada por todo o mundo, além de suas novelas como marketing e propaganda das empresas multinacionais, proliferam ainda os clichês e estereótipos culturais através do futebol, do carnaval e da violência provocada por gangues e organizações criminosas, sem nunca colocar em questão esse Brasil paraíso dos rentistas, esse Brasil que passou de quase quatro séculos de escravização de sua força de trabalho para a superexploração a baixo custo da mão de obra disponível, quando não 
sistematicamente marginalizada e ao mesmo tempo condenada à criminalização e ao genocídio.

Contra essa imagem do Brasil aprisionada nas teias da cultura do dinheiro produzida há mais de 500 anos por essa aranha, que é o capitalismo e seus tentáculos venenosos e contagiantes, que, através desse I Congresso Internacional Brasil in Teias Culturais, e sob o crivo da crítica cultural, nos insurgimos de ponta a ponta no planeta para desfazer esse tecido da aranha venenosa e promover pontos de irrupções, desmantelando o modelo; dobras, promovendo novas conexões; movimentos de subjetivações, liberando o espírito aprisionado; práxis semiológicas, combatendo de ponta a ponta os significados transcendentais; organizações coletivas, recuperando forças de resistência centenárias dos povos excluídos; promover, enfim, novos roteiros de lutas transnacionais que além de uma reparação econômica de longo alcance para os remanescentes e descendentes de povos escravizados, promovam, também, uma consciência política para uma nova luta de classes, em que a questão da acumulação da riqueza de poucos, gerando a miséria de quase todos, seja a palavra de ordem cotidiana da luta política.

Visando a um mapeamento das principais questões desse I Congresso Brasil in Teias Culturais, proponho cinco tópicos, a saber, O ponto e a dobra n. 1, em que descrevo o encontro afetivo de escritores e pesquisadores estrangeiros, e sua área de atuação, com esse Brasil, que escapa às teias da aranha venenosa; O ponto e a dobra n. 2, em que descrevo o papel que escritores e pesquisadores brasileiros, espalhados pelo mundo, mobilizam forças de povos subalternizados nos países hegemônicos, tanto para promover a solidariedade de um Brasil libertário, quanto para explicar e denunciar esse Brasil nas malhas das teias da cultura do dinheiro; $\mathrm{O}$ ponto e a dobra n. 3, em que descrevo como os signos e as lutas coletivas emancipatórias no Brasil se conectam com os signos e lutas coletivas, em outros continentes, sobretudo no continente africano, asiático e nas américas; O ponto e a dobra n. 4, em que descrevo o lugar de epistemologias vigorosas, fora do eixo hegemônico, podem, a partir de agora, orientar o trabalho filosófico e econômico político, a exemplo do perspectivismo indígena nas américas, do comunitarismo africano, do cooperativismo europeu, asiático e latino-americano; e, por fim, O ponto e a dobra n. 5, o da pedagogia 
autobiográfica, em que descrevo a necessidade do trabalho do si no interior das lutas coletivas e emancipatórias. Assim, e em contraponto à teia da cultura do dinheiro, formamos as linhas e pontos de uma teia com cinco lados, todos dobrados e nunca com ângulos retos, que além de duplicar o "pentágono" da teia da cultura do dinheiro, como condição para se tomar distância e implodi-la, essas novas teias, em que o Brasil se coloca sob o crivo da crítica cultural, têm a potência de desdobrar, se multiplicar, se disseminar, se desmontar e remontar onde houver um indivíduo e/ou coletivo oprimido pela cultura do dinheiro.

\section{O ponto e a dobra n. 1}

Há nesse I Congresso Brasil in Teias Culturais, vários pontos de partida disponíveis ao leitor e intérprete para se descrever esse encontro afetivo de escritores e pesquisadores estrangeiros, e sua área de atuação, com esse Brasil, que escapa às teias da aranha venenosa. Eu escolhi a exposição de Claire Varin, romancista e ensaísta da mesa n. 1 intitulada Escritores de uma América Francófona, realizada no dia 02 de outubro. O encontro de Claire se dá com a obra da escritora brasileira Clarice Lispector, encontro esse que teve a potência de mudar sua vida pois desde então veio morar no Brasil para conhecer de perto seus leitores, seus pesquisadores, as instituições de pesquisa de sua obra e daí não só a tese e muitos ensaios, entrevistas e encontros, mas um material simbólico que reorienta sua vida profissional e existencial, e além: ajuda-lhe a construir os dispositivos para muitas lutas coletivas em seu próprio país, a começar pelo que ela chamou de "revolução silenciosa" no Canadá, em que escritores, pesquisadores e artistas, entre outros sujeitos sociais, combatem, combateram e desmontam/desmontaram a teia conservadora que havia se instalado em seu país.

Esse ponto de encontro testemunhado por Claire Varin, essa dobra no plano dos afetos e nos processos de subjetivação, esse ângulo de prospecção e de exploração simbólica, encontra ressonância, por exemplo, no encontro do pesquisador e estudioso de literatura mundial Hu Xudong, da Universidade de Pequim, para quem o seu encontro com a obra de escritores brasileiros como Carlos Drummond de Andrade e João Cabral de Melo Neto, 
não apenas promoveu a emergência de novos crivos e parâmetros para sua leitura e estudos da literatura mundial, colocando esses escritores no mais alto patamar, mas passou a ser o tradutor para o chinês de coletâneas de poemas desses dois escritores, o que tem sido uma festa na recepção da comunidade leitora chinesa. Além de em homenagem a João Cabral ter colocado o nome Tao Tao em sua filha, que em chinês quer dizer: faca só lâmina.

Aqui, alguns versos do poema:

"uma faca só lâmina/assim como uma bala enterrada no corpo,/fazendo mais espesso um dos lados do morto;/assim como uma bala do chumbo mais pesado,/ no músculo de um homem/pesando-o mais de um lado;/qual bala tivesse um vivo mecanismo,/bala que possuísse/um coração ativo/igual ao de um relógio/ submerso em algum corpo,/ao de um relógio vivo/ e também revoltoso,/relógio que tivesse/o gume de uma faca/ e toda a impiedade de lâmina azulada/assim como uma faca/que sem bolso ou bainha/se transformasse em parte de vossa anatomia; qual uma faca íntima/ou faca de uso interno,/habitando num corpo/como o próprio esqueleto/de um homem que o tivesse,/ e sempre, doloroso/de homem que se ferisse contra seus próprios ossos./Seja bala, relógio, ou lâmina colérica,/é contudo uma ausência/ o que esse homem leva/ mas o que não está/nele está como bala:/ tem o ferro do chumbo,/mesma fibra compacta./Isso que não está/nele é como um relógio/pulsando em sua gaiola,/sem fadiga, sem ócios./Isso que não está/nela está como a ciosa/presença de uma faca,/de qualquer faca nova./Por isso é que o melhor/dos símbolos usados/é a lâmina cruel (melhor de Pasmado):/Porque nenhum indica/ essa ausência tão ávida/ como a imagem da faca/ que só tivesse lâmina,/nenhum melhor indica/aquela ausência sôfrega/ que a imagem de uma faca/reduzido à sua boca;/ que a imagem de uma faca/entregue inteiramente/à fome pelas coisas/ que nas facas se sente.

Os testemunhos de Claire Varin, no Canadá, e de Hu Xudong, na China, com escritores brasileiros, podem ainda nos dizer duas coisas: o que fazer para que essa literatura seja lida como uma bíblia às avessas; quais os 
leitores transnacionais eruditos e/ou anônimos que de alguma maneira tem tido acesso aos escritores e artistas clássicos, modernos e contemporâneos brasileiros por todos os continentes e, através dessas duas imagens, como produzirmos centros de cultura brasileira a multiplicarem o prisma dessa teia libertária.

\section{O ponto e a dobra n. 2}

Tivemos também nesse Congresso a presença, em muitas mesas, sobretudo as de número 2, 3, 4, 16 (Estados Unidos) e 19 (França) de escritores e pesquisadores brasileiros, em cujos trabalhos criativos, teóricos, investigativos não só têm anulado o imperativo das línguas de dominação através de suas próprias regras e códigos, fazendo emergir um novo ponto de irrupção em que por dentro dessas línguas de dominação se dobram, se infiltram os valores da ancestralidade afro-brasileira, indígena, e de populações empobrecidas e despejadas, e, com essas dobras, se conectando com os valores dos povos despejados das grandes metrópoles dos centros hegemônicos do capitalismo.

Em muitos trabalhos criativos, teóricos, investigativos, sem aqui citar nomes pela brevidade de construção deste texto, temos uma denúncia contundente da expropriação capitalista das riquezas do Brasil, sem retorno algum ao povo que produz essas mesmas riquezas, bem como, no plano teórico, uma avaliação crítica do sistema intelectual vira-lata, que tomou forma no Brasil, e que tem se preocupado mais em administrar o mal estar de suas subjetividades colonizadas, sem denunciar de forma orgânica sua condição de classe média, protetora das elites nacionais, estas mais empenhadas em hipotecar o país para ganhar comissões e jamais construírem um projeto de nação.

Essa tradução cultural realizada por escritores e pesquisadores brasileiros em atuação nos centros hegemônicos de produção cultural e de expropriação das riquezas do Brasil, é não apenas a forma mais ativa de enfrentamento às teias da cultura do dinheiro e seus tentáculos pegajosos, mas uma condição para se refrear e anular a proliferação dos clichês e 
estereótipos sobre as forças rebeldes e libertárias do Brasil, em movimento, desde a ocupação pelos europeus no início do século XVI.

Resistência indígena, resistência do povo negro escravizado, resistência de populações empobrecidas, nas formas de seus grupelhos e movimentos, bem como em outras formas, ainda por explorar, devem aparecer duplicadas nos livros de intepretação do Brasil promovidos pelo sistema de dominação. Ou seja, se a função desses intérpretes do Brasil, a serviço do imperialismo, tem sido, em muitos casos representativos, a de travar o sistema intelectual contra a consciência política e a luta revolucionária a favor da revolução brasileira, então é incontornável essa tradução cultural realizada por escritores e pesquisadores brasileiros em atuação nos centros hegemônicos de produção cultural e de expropriação das riquezas do Brasil.

\section{O ponto e a dobra n. 3}

Se nos pontos e dobras 1 e 2, tratei, respectivamente, de artistas, escritores e pesquisadores estrangeiros que se encontram com artistas, escritores e pesquisadores brasileiros; e de artistas, escritores e pesquisadores brasileiros, em atuação nos centros hegemônicos, aqui, nesse ponto e dobra n.3, descrevo como os signos e as lutas coletivas emancipatórias no Brasil se conectam com os signos e lutas coletivas, em outros continentes, sobretudo no continente africano, asiático e nas américas.

Na mesa 5, AmeriÁfricas, sobre aquilombamentos, antirracismos e reexistências negras, temos uma pesquisadora e ativista negra, do quilate de Geri Augusto, da Brown University, que faz emergir o ponto da luta organizativa rizomática, num momento está ajudando a organizar as lutas sociais na Tanzânia, em outros momentos, vem ao Brasil aprender com o funcionamento dos movimentos negros; ou ainda a pesquisadora e ativista negra brasileira Ana Lúcia Silva Souza, que conecta as formas de lutas das periferias negras de São Paulo com as de São Tomé e Príncipe ou, simplesmente, como o fez a Profa. Dra. Rachel, da Universidade do Colorado/Denver, através de pesquisa que mostra como o movimento negro nos EUA, além de uma imprensa, uma universidade, e uma série de outras 
organizações, se tem também uma igreja, igrejas, próprias dos negros, nas quais se possa entoar seus cantos, celebrar seus deuses, sem as teias pegajosas do deus-dinheiro.

Esse ponto das lutas culturais organizativas, com suas dobras rizomáticas, se expande em outras mesas 13, 14, 15, 16 e 17, da Teia Brasil Áfricas, proposta pela pesquisadora Ana Rita Santiago, Profa. Associada da Universidade Federal do Recôncavo e do corpo permanente do Programa de Crítica Cultural, em que seus mais de 20 pesquisadores em movimento por um dezena de universidades brasileiras e africanas, sobretudo as universidades africanas em países de língua portuguesa, em que, para além desse ponto que irrompe tratando das lutas organizativas por vários continentes, se chega a um platô de forte intensidade: a de que o Brasil, em vez de ser uma invenção da Europa ou contemporaneamente, uma invenção dos EUA, é, antes de tudo e principalmente, uma construção social coletiva através de saberes milenares africanos.

E basta escavarmos: da geologia e formação da terra e seus oceanos, passando pela cultura egípcia, em contraponto à cultura greco-latina, e a desmontagem de toda cronologia e formas de temporalidade impostas pelo imaginário judaico-cristão e seu espraiamento pelo projeto da modernidade ocidental.

Para ampliar essa festa da desmontagem do imperativo ocidental sobre a construção do Brasil e sua civilização, temos ainda as mesas 6, 7, 8, 9, 10, 11 e 12 sobre os BRICS, em que através do mandarim como uma segunda língua em escolas públicas brasileiras teremos a possibilidade de implementar novas lutas pelos direitos linguísticos e literários envolvendo os bilinguismos línguas indígenas e português/línguas africanas e português, mas, principalmente, organizar a luta política em termos de economia política socialista.

\section{O ponto e a dobra n. 4}

A organização da luta política, sob um viés socialista, tem seu ponto de irrupção a partir de um dos "semáforos" apontados pelo pesquisador Prof. Dr. José Castiano, da Universidade de Maputo - Moçambique, e integrante da 
mesa 13 (Desobediência Epistêmica: um desafio à crítica cultural) para quem a modernidade na América começa com a revolução no Haiti, pondo por terra todo o projeto da modernidade ocidental em seu viés histórico, filosófico e estético.

Se a modernidade na América tem seu ponto de partida com a revolução do Haiti (1791-1804), em que além da abolição completa da escravização do povo negro, pelo próprio povo negro escravizado, se enxota (o mesmo massacra) os brancos e se se apropria de todas as propriedades, repartindo-as pelas famílias e comunidades em luta, então é toda a temporalidade histórica, e por toda a América, que precisa ser repensada; então é toda a função do pensamento revolucionário e filosófico que precisa ser repensada e socializada através educativas e pedagógicas; então é todo um novo trabalho estético, que combine todos os signos de luta, que precisa ser engendrado.

Essa outra noção de modernidade, fora do eixo europeu e estadunidense, faz conectar o perspectivismo indígena, em que coisas e animais têm potência anímica; faz conectar os saberes de resistência que atravessam as lutas populares, em geral condenadas como senso comum pela lógica do bom senso ocidental; faz conectar, ainda, todas as formas de associativismo, comunitarismo, milenares, e que envolvem povos africanos, asiáticos e nas américas.

Assim, essa outra noção de modernidade, interposta pela revolução haitiana, tem a potência de refazer epistemologicamente todas as ordens de despejo a que foram relegadas as populações originárias da América, bem como as populações que foram traficadas de vários continentes para as Américas, hoje dizimadas ou empobrecidas ao extremo de suas vidas e existências. E o que é pior: esse cenário se desdobra pelas periferias de todos os centros hegemônicos, onde ninguém é cidadão ou cidadã, mas apenas coisas descartáveis.

\section{O ponto e a dobra n. 5}

Identifiquei o ponto da pedagogia autobiográfica, para o trabalho do si no interior das lutas coletivas e emancipatórias, em muitas mesas, mas 
gostaria partir da mesa 4, sobre a celebração dos 100 anos de nascimento de Clarice Lispector, em que o pesquisador Christopher Larkosh, da Universidade de Massachusetts at Dartmouth, EUA, “relendo Clarice num país de mulheres migrantes", lateralmente e meio que pedindo desculpas, destaca o papel de Carolina de Jesus para se pensar o Brasil e que, suplementando essa constatação, diríamos, ainda, não apenas para se pensar o Brasil, mas para se pensar o mundo contemporâneo, dominado pelas teias da cultura do dinheiro. Além da mesa 4, destacar a comunicação da pesquisadora Maria Conceição Passegi, da Universidade Federal do Rio Grande do Norte, que na mesa 25, sobre letramentos, narrativas e formação de educadores na América Latina, estimula as narrativas de si, envolvendo comunidades de professores(as), como se fosse num círculo de cultura de Paulo Freire.

Trata-se, portanto, do trabalho do si no interior das lutas coletivas e emancipatórias, e não trabalho do si, em si, e para si mesmo. Isso é fundamental e tem por dobras o combate ao despejo ontológico promovido pela retórica judaico-cristã que atravessa o humanismo ocidental que, a rigor e observando os massacres em nome de Deus, do Rei, do Estado e do Capital, não nada de humanismo, a menos que e esse "humanismo" falso se reduza aos "homens de bem", o branco, rico, protegido pelas forças armadas, detentores de toda a riqueza parasitada; e também por dobra, a retórica stalinista, coletivista e mecanicista, de que o indivíduo, o si, é uma doença burguesa.

Operando entre uma retórica e outra, a pedagogia autobiográfica, é como se fosse uma conversa entre amigos, marcada por uma profunda amizade, con sentida, para se falar principalmente das ordens despejo (linguístico, cultural, territorial e ontológica) e que pode ocorrer não somente nas escolas, mas nos equipamentos de cultura, nos movimentos sociais, nas associações de moradores, de casa em casa, de porta em porta, como uma cruzada pela emancipação humana do jugo do deus-dinheiro e suas violências legitimadas.

\section{Palavras finais}

Recorro, para encerrar este texto, à mesa 17, da Teia Brasil - Áfricas, intitulada Problemas do Mundo e Trilhas de Sustentabilidade, em que 
pensamos no seguinte roteiro para nossos trabalhos libertários e fora do eixo e dos imperativos hegemônicos:

- Roteiro 1: Realizar, ao menos uma vez por ano, novos congressos Brasil in Teias Culturais;

- Roteiro 2: Organizar, sempre que possível e durante o ano letivo em cada país, programas de disciplinas em comum, pondo os estudantes, de todos os níveis, em contato com várias culturas e formas de ensino aprendizagem e com isso agregando valor internacional aos históricos desses estudantes;

- Roteiro 3: Realizar projetos de extensão internacionais dando a ver e a conhecer outros modos de produção e de organização comunitária;

- Roteiro 4: Recorrer a organismos internacionais como a ONU a fim de que se crie algum dispositivo de combate a pobreza extrema;

- Roteiro 5: Inserir nos currículos escolares de todos os níveis a questão da economia política emancipatória a fim de que as riquezas locais, regionais, nacionais, internacionais sejam debatidas no cotidiano e o setor público seja envolvido nesse debate;

- Roteiro 6: Incluir as empresas locais no rol das discussões políticas, cobrando delas a sua função social e de apoio à redução das desigualdades;

- Roteiro 7: Criar condições públicas e comunitárias para que todos os segmentos religiosos explicitem seus vínculos com o capital, com a história e com as formas de poder de Estado; e,

- Roteiro 8: Proliferar os círculos de cultura para que os sujeitos sociais possam dispor de uma língua emancipatória e libertária.

Cada sujeito, individual ou em seus coletivos, pode, portanto, identificar o ponto de violência opressora promovido pelo capital e/ou pelo Estado, como seu gerente, e a partir desse ponto empreender uma dobra, seja 
essa dobra começando por uma pergunta, em condições de suspender uma série; seja através de trabalhos organizativos e persistentes. Se onde há um ser humano, nesse estágio atual da (des)humanidade, há um tentáculo da teia venenosa do capital, nunca é demais afirmar que, em contraponto, há no mesmo lance e no instante da pergunta, um antídoto em potencial, capaz de desfazer essa teia e empreender novas, em disseminações libertárias.

\section{Referências}

AGAMBEN, Giorgio. Infancia e historia: destrucción de la experiência y origen de la historia. Trad. Silvio Mattoni. Córdoba, Argentina: Adriana Hidalgo Editora, 2001.

AGAMBEN, Giorgio. O que resta de Auschwitz: o arquivo e a testemunha Homo Sacer III. Trad. Selvino J. Assmann. São Paulo: Boitempo. 2008.

DELEUZE, Gilles. Nietzsche. Trad. Alberto Campos. Lisboa, Portugal: Edições 70 Ltda. 2007.

GONZÁlEZ, Horácio. A Comuna de Paris: os assaltantes do céu. São Paulo: Brasiliense, 1989.

LÊNIN, Vladimir Ilitch. O Estado e a revolução. Trad. Henrique Canary. São Paulo: Editora Instituto José Luis e Ros Sundermann, 2005.

MÉSZÁROS, István. O século XXI: socialismo ou barbárie? Trad. Paulo Cesr Castanheira. São Paulo: Boitempo, 2003.

SANTOS, Osmar Moreira dos. A luta desarmada dos subalternos. Belo Horizonte: Editora UFMG, 2016.

SANTOS, Osmar Moreira dos. Platô de Crítica Cultural na Bahia: Por um roteiro de trabalho científico transgressor. In: ATAÍDE, Cleber et al. (Org.). Cartografia GelNE: 20 anos de pesquisas em Linguística e Literatura (vol. II). Campinas, São Paulo: Pontes Editores, 2019.

SANTIAGO, Silviano. O Cosmopolitismo do pobre: crítica literária e crítica cultural. Belo Horizonte: Editora UFMG, 2004.

SCHWARZ, Roberto (Org.). Os pobres na literatura brasileira. São Paulo: Brasiliense, 1983.

SLOTERDIJK, Peter. Regras para o parque humano: uma resposta à carta de Heidegger sobre o humanismo. Trad. José Oscar de Almeida Marques. São Paulo: Estação Liberdade, 2000. 
SLOTERDIJK, Peter. O desprezo das massas: ensaio sobre lutas culturais na sociedade moderna. Trad. José Oscar de Almeida Marques. São Paulo: Estação Liberdade, 2002.

TROTSKI, Leon. Literatura e revolução. Trad. Luiz Alberto Moniz Bandeira. Rio de Janeiro: Jorge Zahar Editor, 2007.

Recebido em 20 de novembro de 2020

Aceito em 15 de dezembro de 2020 